\title{
Designing and Evaluating COVID-19 Protocols for an Office-Based Opioid Treatment Program in an Urban Underserved Setting
}

\author{
David T. O'Gurek, MD, FAAFP
}

Background: Despite changing federal regulations for providing telehealth services and provision of controlled substances during the COVID-19 pandemic, there is little guidance available for office-based opioid treatment (OBOT) programs integrated into primary care settings.

Purpose: (1) Develop disaster-preparedness protocols specific to the COVID-19 pandemic for an urban OBOT program, and (2) evaluate the impacts of the protocol and telehealth on care.

Methods: Disaster-preparedness protocols specific to the COVID-19 pandemic were developed for an urban OBOT program, implemented on March 16, 2020. Retrospective chart review compared patients from January 1, 2020 to March 13, 2020, to patients from March 16, 2020 to April 30, 2020, abstracting patient demographics and comparing show and no-show rates between studied groups.

Results: The disaster-preparedness protocol was developed under a deliberative process to address social issues of the urban underserved population. Of 852 visits conducted between Jan 1, 2020, and April 30, 2020, a 91.7\% show rate $(\mathrm{n}=166 / 181)$ was documented for telemedicine visits after protocol implementation compared with a $74.1 \%$ show rate $(n=497 / 671)$ for routine in-person care $(P=.06)$ without significant differences between the study populations. The no-show rate was significantly lower after protocol implementation $(8.3 \%$ vs $25.9 \% ; P<0.05)$.

Conclusions: OBOTs require organized workflows to continue to provide services during the COVID-19 pandemic. Telemedicine, in the face of relaxed federal regulations, has the opportunity to enhance addiction care, creating a more convenient as well as an equally effective mechanism for OBOTs to deliver care that should inform future policy. ( $\mathrm{J}$ Am Board Fam Med 2021;34:S136-S140.)

Keywords: Controlled Substances, COVID-19, Disasters, Opioids, Pandemics, Primary Health Care, Retrospective Studies, Substance Abuse, Telemedicine, Vulnerable Populations

\section{Introduction}

Amid the global pandemic of coronavirus disease 2019 (COVID-19), medicine has rapidly evolved to deliver care in different ways. While the Substance Abuse and Mental Health Services Administration

This article was externally peer reviewed.

Submitted 8 May 2020; revised 25 July 2020; accepted 30 July 2020.

From the Department of Family \& Community Medicine, Lewis Katz School of Medicine at Temple University, Philadelphia, PA.

Funding: The project was funded, in part, by the Pennsylvania Coordinated Medication Assisted Treatment (PacMAT) Program, Department of Health, Commonwealth of Pennsylvania.

Conflict of interest: The author has nothing to disclose (no potential, perceived, or real conflicts of interest) and had full access to and control of the study.

Corresponding author: David T. O'Gurek, MD, FAAFP, Department of Family \& Community Medicine, Lewis Katz School of Medicine at Temple University, 1316 W Ontario
(SAMHSA) provides guidance for licensed outpatient treatment programs (OTP), ${ }^{1}$ there is little guidance for office-based opioid treatment (OBOT) programs that have developed within primary care settings across the country. Continuing provision of services, including buprenorphine for individuals struggling with opioid use disorder (OUD), are essential care elements that must be accessible alongside an ongoing overdose crisis. With the declaration of a public health emergency, exceptions to the Controlled Substances Act allow for initial visits to occur through telemedicine using an audiovisual, 2-way interactive communication system provided additional state regulations are not imposed. ${ }^{2}$ Furthermore, the Office for Civil Rights (OCR) created provisions such that they will

Street, Philadelphia, PA 19140, Phone: (215)707-8961, Fax: (215)707-5850 (E-mail: david.ogurek@temple.edu). 
not impose penalties for non-compliance with the regulatory requirements under the HIPAA during the COVID-19 nationwide public health emergency. ${ }^{3}$

Previous studies have indicated the role of telemedicine, particularly for the delivery of these services to rural communities. ${ }^{4}$ Many programs in primary care settings have not been delivering such services through telemedicine. However, with the need to either eliminate or mitigate risk for both patients as well as health care workers during the pandemic, OBOTs are being called on to use technology to maintain continuity of services for patients with OUD on buprenorphine therapy. In this study, we evaluated the early impacts of a disaster management plan and telemedicine protocols on show rates at an OBOT as a marker of access to care.

\section{Methods}

\section{Protocol Development}

Protocols were developed based on functional and operational abilities of the program as well as oriented toward addressing barriers to access including telephone access. Protocols were implemented on March 16, 2020. All patients were contacted before their appointment by our program staff with a phone script that described the telemedicine process, including the option of a telephone or video visit. Based on patient accessibility and interest, the patient selects whether the visit will occur via phone or via video chat. The phone triage involved sequenced questioning that ensured a key message that they would not go without their medication at this time and that efforts were directed to ensuring continuous access for medications regardless of social or economic barriers (Figure 1). For individuals who physically presented to the clinic, standard COVID screening remained intact but protocols were developed to ensure the patient could have existing and ongoing telephone contact follow-up (Figure 2). Telemedicine visits conducted either by phone or by video included an overall assessment of current patient status, episodes of return to use, cravings, stressors and triggers, and identification of current aftercare (counseling and behavioral health services). Additional care concerns, medical treatment of comorbidities, and plans to address social needs were also included as part of the visit. As with prior in-person visits, warm handoffs to acute care settings, social service facilities, and community benefit organizations was completed. If a patient needed to present for injectable medication, COVID screening occurred and the patient's in-person visit was maintained.

\section{Setting}

This study took place at an OBOT program housed with the Department of Family \& Community Medicine at an urban university medical center that cares for a largely underserved population.

\section{Quantitative Data Collection \& Analysis}

Using a retrospective chart review, we reviewed visits from Jan 1, 2020, through April 30, 2020. Descriptive statistics were conducted including percentages of demographic variables as well as noshow rates between visits conducted before protocol implementation (January 1, 2020, to March 13, 2020) and after protocol implementation (March 16, 2020 to April 30, 2020). We utilized $\chi^{2}$ tests to compare populations between study periods.

\section{Results}

A total of 852 visits were conducted between January 1, 2020 and April 30, 2020, with 671 visits (289 individual patients) occurring between January 1, 2020 and March 13, 2020, and 181 visits (141 individual patients) occurring between March 16, 2020 and April 30, 2020. Patients in the OBOT program were more likely to be male sex $(62.7 \%$ seen; $64.0 \%$ scheduled), identify as Black/African American (42.2\% seen; $40.9 \%$ scheduled), and have Medicaid insurance $(74.9 \%$ seen; $75.1 \%$ scheduled). Demographic characteristics between those individuals seen and the total patients scheduled were similar (see Table 1). While the show rates for patients pre-and post-protocol implementation were not significantly different $(P=.06)$, the noshow rates significantly reduced with utilization of the telemedicine protocols $(P \leq .05)$ (Figure 3 )

\section{Discussion}

Previous evidence has suggested the effectiveness of telemedicine services as a means of increasing access to services. ${ }^{5}$ Early data suggest that disaster-preparedness protocols in a time of COVID have enabled continued access for patients seen at the program with improvements in show rates from $74.1 \%$ to $91.7 \%(P=.06)$. Factors that may be associated with improved access include enhanced convenience, 
Figure 1. Pre-visit phone triage process for COVID protocol for OBOT program. Abbreviations: OBOT, Office Based Opioid Treatment; CDC, Centers for Disease Control; RN, Registered Nurse; ID, Identification.



If you do begin to feel sick with fever, cough, or shortness of breath, please call system COVID hotline before coming in so we can appropriately arrange for your care

reduced travel time, and cost savings ${ }^{6}$ in a population that struggles with limited resources.

As OBOT programs seek guidance for protocols and practices to continue provision of care during the pandemic, these protocols can be individualized and implemented to meet the program community's needs. This individualization that specifically addresses the unique needs of the community served is essential to early successes. Previous studies have indicated no difference in face-to-face and telemedicine

Figure 2. Process for patients physically presenting to OBOT program as part of COVID protocol. Abbreviations: OBOT, Office Based Opioid Treatment; MA, Medical Assistant.

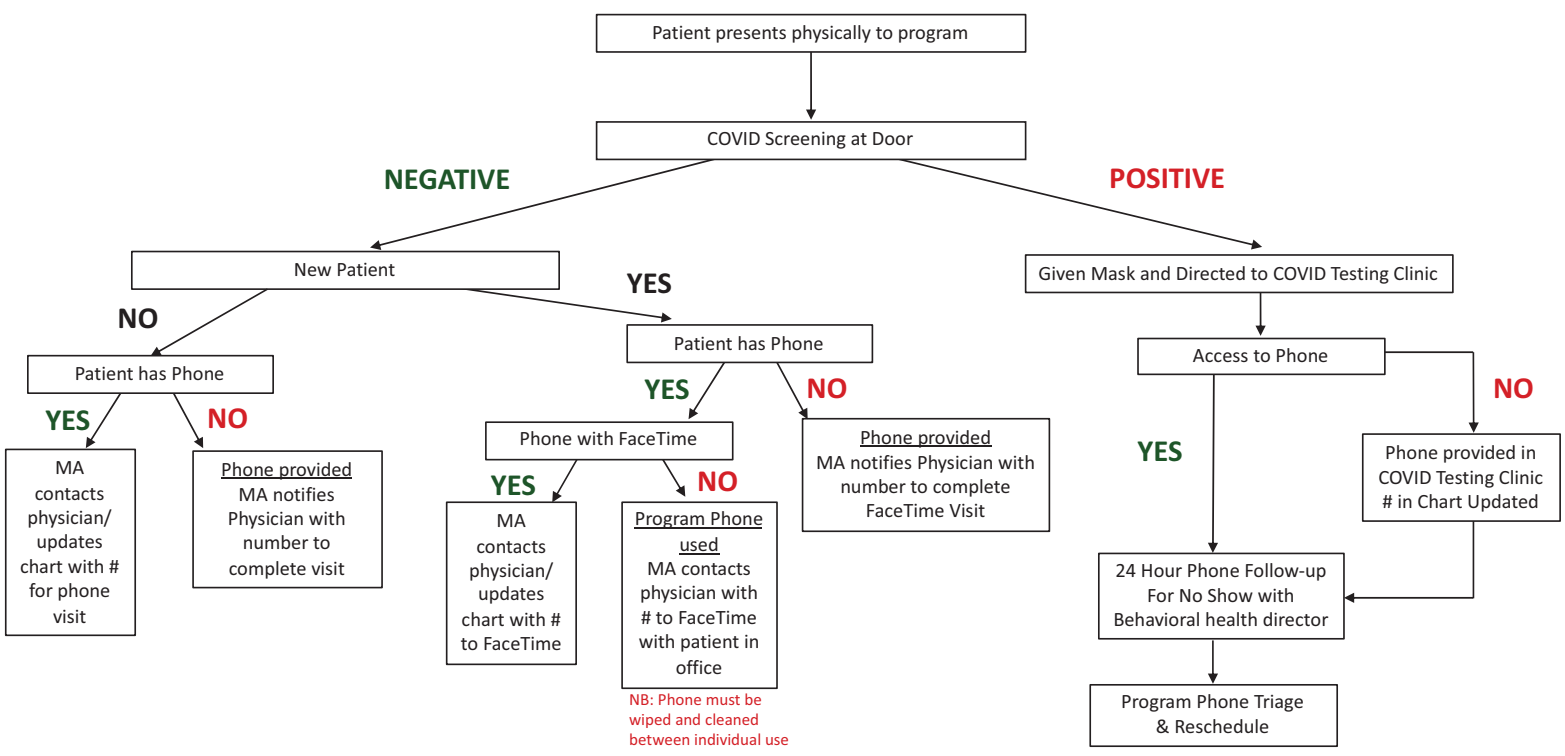


Table 1. Demographic Characteristics of Arrived and Scheduled Visits at an OBOT Program

\begin{tabular}{|c|c|c|c|c|c|c|}
\hline & $\begin{array}{l}\text { Arrived Patients } \\
\text { Before protocol } \\
\text { implementation } \\
\text { (January } 1 \text { to } \\
\text { March } 13,2020) \\
\mathrm{n}=214(\%)\end{array}$ & $\begin{array}{l}\text { Arrived Patients } \\
\text { after protocol } \\
\text { implementation } \\
\text { (March } 16 \text { to April } \\
30,2020) \\
\mathrm{n}=132(\%)\end{array}$ & $P$ value & $\begin{array}{c}\text { Scheduled } \\
\text { Patients Before } \\
\text { protocol imple- } \\
\text { mentation } \\
\text { (January } 1 \text { to } \\
\text { March 13, 2020) } \\
\text { n = 289(\%) }\end{array}$ & $\begin{array}{c}\text { Scheduled } \\
\text { Patients after pro- } \\
\text { tocol implementa- } \\
\text { tion (March } 16 \text { to } \\
\text { April 30, 2020) } \\
\text { n }=141(\%)\end{array}$ & $P$ value \\
\hline \multicolumn{7}{|l|}{ Demographic Characteristics } \\
\hline \multicolumn{7}{|l|}{ Sex } \\
\hline Female & $74(34.6)$ & $55(41.7)$ & .58 & $98(33.9)$ & $57(40.4)$ & .57 \\
\hline Male & $140(65.4)$ & $77(58.3)$ & .72 & $191(66.1)$ & $84(59.6)$ & .73 \\
\hline \multicolumn{7}{|l|}{ Race \& Ethnicity } \\
\hline Black/African American & $86(40.2)$ & $60(45.5)$ & .76 & $112(38.8)$ & $64(45.4)$ & .60 \\
\hline Hispanic, non-white & $47(22.0)$ & $20(15.2)$ & .38 & $64(22.1)$ & $22(15.6)$ & .36 \\
\hline White & $77(36.0)$ & $50(37.9)$ & .96 & $103(35.6)$ & $51(36.2)$ & .99 \\
\hline Other & $4(1.9)$ & $2(1.5)$ & .97 & $8(2.8)$ & $4(2.8)$ & 1.0 \\
\hline \multicolumn{7}{|l|}{ Insurance } \\
\hline Commercial & $12(5.6)$ & $10(7.6)$ & .78 & $16(5.5)$ & $10(7.1)$ & .83 \\
\hline Medicaid & $158(73.8)$ & $101(76.5)$ & .91 & $215(74.4)$ & $108(76.6)$ & .97 \\
\hline Medicare & $27(12.6)$ & $20(15.2)$ & .82 & $39(13.5)$ & $21(14.9)$ & .94 \\
\hline Self-Pay & $12(5.6)$ & $1(0.8)$ & .08 & $4(6.6)$ & $1(0.7)$ & .03 \\
\hline Age, years* & 44.1 & 44.6 & & 43.7 & 44.8 & \\
\hline
\end{tabular}

*Age in years signifies average age. OBOT, Office Based Opioid Treatment.

buprenorphine visits with regards to additional substance use, treatment retention at 90 and 365 days, ${ }^{4}$ relapse, hospitalization, mortality, and illegal activity. ${ }^{7}$ Furthermore, existing and newly developed online telemedicine recovery resources through counseling and recovery meetings can facilitate continued behavioral health therapy as a component of delivering the comprehensive care needed for recovery.

Figure 3. Comparison of show rates and no-show rates for patients pre-and post-implementation of COVID protocols for Office Based Opioid Treatment (OBOT) program.

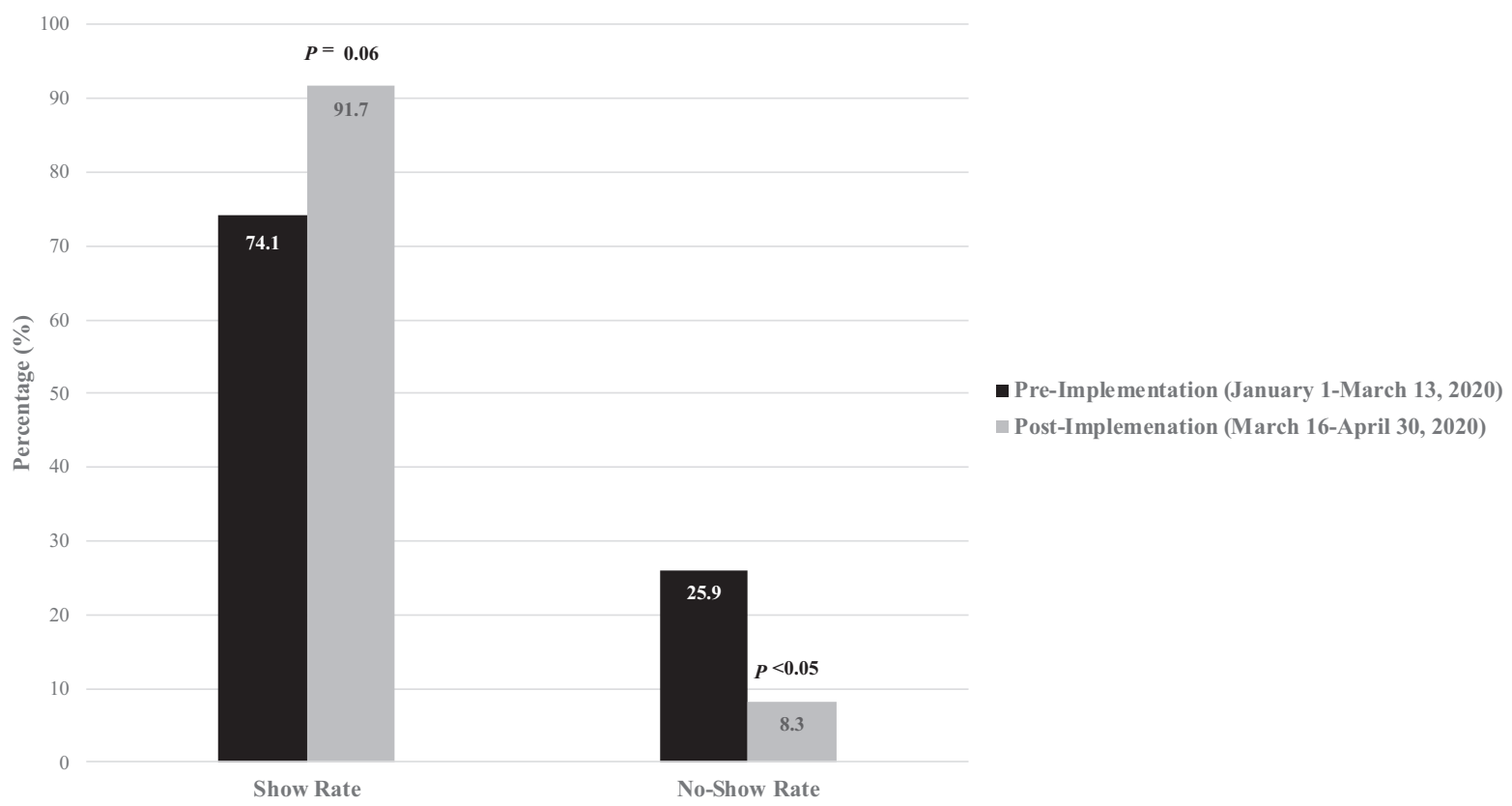


As time progresses and OBOT programs develop unique strategies to address the needs of the communities they serve, research and data are imperative to inform future policy. With more efficient use of provider time supported by lower no-show rates in this study, telemedicine should remain a part of OBOT programs into the future with added benefits of cost savings on rental of office space or staff utilization. Specified protocols on how to incorporate drug screening and frequency of in-office appointments will also need to be decided. However, ensuring low-barrier opportunities unhampered by regulations will be critical to fostering and promoting further integration of telemedicine into existing and new OBOT programs in the future. Current opportunities allow for OBOT programs to direct both federal and state regulations that can address some of the preceding barriers to implementation of telemedicine such as start-up costs for technologies that are HIPAA-compliant, limited broadband particularly in rural areas, and difficulty with integration of telemedicine behavioral health services with 42 Code of Federal Regulations Part 2. While these changes occurred amid a pandemic, it is critical to learn from them what process and protocols will look like beyond the pandemic.

\section{Limitations}

Our main limitation at this time includes a small sample size as well as a lack of study of engagement in treatment. Protocols have only been implemented since mid-March and therefore only reflect 1.5 months of data. Furthermore, the 181 visits reflect 141 individual patients and therefore the study period does not allow for monitoring for retention in care. As these protocols were developed for disaster-preparedness related to the current COVID pandemic, they do not serve as long-term protocols for a telemedicine program; however, can be utilized to develop such protocols pending regulations around telemedicine post-COVID. With development of such protocols, evaluating retention in care, monitoring treatment with engagement with aftercare, learning the results of drug testing during in-person visits, such as the presence of buprenorphine and appropriate buprenorphine:norbuprenorphine ratios, will be critical.

\section{Conclusions}

The program's early experiences with COVID-19 disaster-preparedness protocols and use of telemedicine for delivering addiction care show early success and promise for the future. Future research as well as an evolving pandemic will undoubtedly require refinement and improvement of workflows to sustain continuation of services for patients with OUD during the pandemic and beyond.

To see this article online, please go to: http://jabfm.org/content/ 34/Supplement/S136.full.

\section{References}

1. Substance Abuse and Mental Health Services Administration. Disaster Planning Handbook for Behavioral Health Treatment Programs. Technical Assistance Publication (TAP) Series 34. HHS Publication No. (SMA) 13-4779. Rockville, MD: Substance Abuse and Mental Health Services Administration, 2013.

2. US Department of Justice Drug Enforcement Administration. COVID-19 Information Page. 2020. Available at: https://www.deadiversion.usdoj.gov/ coronavirus.html. Accessed March 28, 2020.

3. US Department of Health and Human Services. Notification of Enforcement Discretion for Telehealth Remote Communications During the COVID-19 Nationwide Public Health Emergency. 2020. Available at: https://www.hhs.gov/hipaa/for-professionals/specialtopics/emergency-preparedness/notification-enforcementdiscretion-telehealth/index.html. Accessed March 28, 2020.

4. Zheng W, Nickasch M, Lander L, et al. Treatment Outcome Comparison Between Telepsychiatry and Face-to-face Buprenorphine Medication-assisted Treatment for Opioid Use Disorder: A 2-Year Retrospective Data Analysis. J Addict Med 2017;11:138-44.

5. Hilty DM, Ferrer DC, Parish MB, Johnston B, Callahan EJ, Yellowlees PM. The effectiveness of telemental health: a 2013 review. Telemed J E Health 2013;19:444-54.

6. Yang Y'T, Weintraub E, Haffajee RL. Telemedicine's role in addressing the opioid epidemic. Mayo Clin Proc 2018;93:1177-80.

7. Eibl JK, Gauthier G, Pellegrini D, et al. The effectiveness of telemedicine-delivered opioid agonist therapy in a supervised clinical setting. Drug Alcohol Depend 2017;176:133-8. 